\title{
Temporomandibular eklem düzensizliği bulunan hastalarda kulak semptomları prevelansının araştırılması
}

\author{
Günay Yapıcı Yavuz(0000-0002-1093-6297) ${ }^{\alpha}$, Aydın Keskinrüzgar(0000-0001-5735-6890 ${ }^{\alpha}$, \\ Mahmut Koparal(0000-0003-1817-1230) ${ }^{\alpha}$, Mustafa Utkun(0000-0003-37359714) ${ }^{\alpha}$, Göksel Şimşek Kaya(0000-0003-3398-5574) ${ }^{\beta}$
}

Selcuk Dent J, 2020; 7: 220-225 (Doi: 10.15311/selcukdentj.515895)

Basvuru Tarihi: 21 Ocak 2019 Yayına Kabul Tarihi: 10 Haziran 2019

ÖZ

Temporomandibular eklem düzensizliği bulunan hastalarda kulak semptomları prevelansının araştırılması

Amaç: Temporomandibular eklem düzensizliği bulunan hastalarda temporomandibular eklem, çiğneme kasları ve ilişkili olduğu yapılarda çeşitli semptomlara sebep olabilmektedir. Yakın komşulukta olduğu yapılardan olan kulakta kulak ağrısı, kulak çınlaması, kulakta dolgunluk hissi, kulak kaşıntısı, işitmede azalma, baş dönmesi, denge kaybı gibi semptomlara neden olabilmektedir. $\mathrm{Bu}$ çalışmanın amacı, temporomandibular eklem düzensizliğine eşlik eden kulak semptomları prevelansının değerlendirilmesidir.

Gereç ve Yöntem: Retrospektif çalışma Ocak 2017-Aralık 2017 tarihleri arasında Adıyaman Üniversitesi Diş Hekimliği Fakültesi Ağız, Diş ve Çene Cerrahisi AD'na TME bölgesinde ağıı ve/veya disfonksiyon şikayeti ile başvuran 214 hasta ile planlandı. Hastaların seçimi TMD/ATK'ye göre yapıldı. TMD teşhisi konan hastalarda kulak ağrısı, kulak çınlaması, kulakta dolgunluk hissi, kulak kașıntısı, ișitmede azalma, baș dönmesi, denge kaybı semptomlarının varlığı araştıııdı. Hastalara kulak semptomlarını var veya yok şeklinde değerlendirebilecekleri formlar dolduruldu. Semptomların şiddeti ile bilgi edinilmedi.

Bulgular: 214 TMD hastasının 65 'inde kulak semptomuna rastlanmadı. 149 hastada ise en az bir kulak semptomu gözlendi. 149 hastanın 117'sinde kulak ağrısı (\%78.5), 77'sinde kulak çınlaması (\%51.7), 56'sında kulakta dolgunluk hissi (\%37.6), 50 'sinde kulak kaşıntısı (\%33.6), 3'ünde işitmede azalma (\%2), 61 'inde bas dönmesi (\%40.9) ve 50'sinde denge kaybı (\%33.6) tespit edildi. 149 hastanın 120'i kadın (\% 80.5), 29'i erkektir. (\%19.5)

Sonuç: TMD'ye kulak semptomları arasında en fazla kulak ağrısı, ikinci sırada kulak çınlaması ve en az ise işitmede azalma eşlik etmektedir.

\section{ANAHTAR KELIMELER}

Kulak ağrısı, kulak çınlaması, kulak semptomları, TMD

Temporomandibular eklem düzensizlikleri (TMD), temporomandibular eklem (TME) ve/veya çiğneme kaslarında ağrı ve disfonksiyon dahil olmak üzere çeşitli belirti ve semptomlar ile karakterizedir. Ağrı ve disfonksiyon bu bölgeler dışında yüz ve boyun bölgesi örneğin kafanın temporal, oksipital ve frontal bölgeleri ve

\section{ABSTRACT}

A study of the prevalence of otolaryngologic symptoms in patients with temporomandibular joint dysfunction

Background: Temporomandibular joint dysfunction can lead to various symptoms in the temporomandibular joint, masticatory muscles, and related structures in patients. It can lead to symptoms like otalgia, tinnitus, aural fullness, itchiness in the ear, hearing loss, vertigo, and loss of balance in the ear, a structure of close proximity. The purpose of this study is the evaluation of the prevalence of otolaryngologic symptoms that accompany temporomandibular joint dysfunction.

Methods: The retrospective study was planned with 214 patients referred with pain and/or complaints of dysfunction to the Adıyaman University Faculty of Dentistry Maxillofacial Surgical Department between the dates of January - December 2017. The selection of the patients was done based on TMD/ATK. The presence of the symptoms of otalgia, tinnitus, aural fullness, itchiness in the ear, hearing loss, vertigo, and loss of balance in was researched in patients diagnosed with TMD. The patients were asked to fill out forms in which they were able to assess their otolaryngologic symptoms as either present or not. Information was not obtained regarding the severity of the symptoms.

Results: No otolaryngologic symptoms were encountered in 65 of the 214 TMD patients. In 149 patients, at least one otolaryngologic symptom was observed. Of the 149 patients, otalgia was detected in $117(78.5 \%)$, tinnitus in $77(51.7 \%)$, aural fullness in $56(37.6 \%)$, itchiness in the ear in $50(33.6 \%)$, hearing loss in $3(2 \%)$, vertigo in $61(40.9 \%)$, and loss of balance in $50(33.6 \%)$. Of the 149 patients, $120(80.5 \%)$ were female and $29(19.5 \%)$ were male.

Conclusion: Among the otolaryngologic symptoms of TMD, otalgia most accompanies the disease, tinnitus is the second most prevalent, and hearing loss is the least encountered symptom.

\section{KEYWORDS}

Otalgia, tinnitus, aural symptoms, TMD

kulak çevresi etkilemektedir. ${ }^{1-3}$ Anatomik olarak yakın komşuluktaki kulak, mandibula, yüz, baş ve boyun bölgesindeki çeşitli şikayetler TMD'den kaynaklı olabilmektedir. Kulak trigeminal sinir (V), fasiyal sinir (VII), glossofaringeal sinir (IX), vagus $(X)$ ve otonomik sinirler ile innerve olmaktadır. TME V. ve VII. kraniyal

\footnotetext{
${ }^{\alpha}$ Adıyaman Üniversitesi Diş Hekimliği Fakültesi Ağız, Diş ve Çene Cerrahisi Anabilim Dalı, Adıyaman

$\beta$ Akdeniz Üniversitesi Diş Hekimliği Fakültesi Ağız, Diş ve Çene Cerrahisi Anabilim Dalı, Antalya
} 
sinirler ile ve kulak yapılarına çok yakın olan (korda tympani gibi) iletişim dalları ile innerve olmaktadır. ${ }^{4}$ Böylelikle TME'de bulunan düzensizlikler yakın anatomik komşulukta bulunduğu için kulakta şikayetlere sebep olabilmektedir. Ayrıca literatürde TMD bulunan hastalarda kulak semptomları birkaç patofizyolojik mekanizma ile açıklanmıştır. Bunlar, tensör timpani ve tensör palatin kaslarının disfonksiyonu ${ }^{5}$, işitme tüpünün disfonksiyonu ${ }^{6}$, petrotimpanik fissürde girişim ${ }^{7}$ ve sphenomandibular ligament yoluyla ön malleoler ligamentindeki gerginlik ${ }^{8}$ ile ilişkili çiğneme kaslarındaki spazmlardır. Ancak, bu mekanizmalar hiçbir zaman hipotez aşamasını geçemediler. ${ }^{9}$ TMD bulunan hastalarda kulak ağrısı, kulak çınlaması, duymada azalma, kulak kaşıntısı, baş dönmesi, sese tahamülsüzlük gibi kulağa ait semptomların sıklıkla karşılaşıldığını bildiren çalışmalar bulunmaktadır. ${ }^{1-4, ~ 9-11}$ TMD bulunan hastalar kulak ağrısı, kulak çınlaması, baş dönmesi, duymada azalma gibi kulağa ait semptomlardan şikayetçi olabilmektedirler., ${ }^{1,49-11}$ Kulak ağrısı çiğneme sisteminin bozulmasında çok yaygın görülen fonksiyonel bir semptomdur. TMD bulunan hastalarda kulak ağrısı görülme oranı \%5 ile \%42'dir. ${ }^{1,12}$ Kulak çınlaması kulakların birinde veya ikisinde dışarıdan akustik uyaran gelmeden fakat kafanın içinde oluşan akustik duyumlardır. Hastalar kulak çınlamasını gıcırtı, ıslık sesi, kağıt hışırtısı veya deniz uğultusu şeklinde tanımlayabilmektedirler. ${ }^{10}$ TMD bulunan hastalarda kulak çınlaması oranının \%33 ile \%76 arasında olduğu bildirilmiştir. ${ }^{1,3,13}$ Vertigo veya baş dönmesi prevelansı TMD hastalarında $\% 40$ ile \% 70 arasında değiştiği bildirilmiştir. ${ }^{1,3}$

Yapılan çalışmalar TMD bulunan hastalarda, TMD bulunmayanlara göre kulak ile ilgili şikayetlerin daha sık olduğunu göstermektedir. ${ }^{14,15}$ Ancak yapılan çalışmalarda daha çok kulak ağrısı, kulak çınlaması, baş dönmesi ve duymada azalma semptomları değerlendirilmiştir. ${ }^{1-4,11}$ Çalışmamızda kulak ağrısı, kulak çınlaması, kulakta dolgunluk hissi, kulak kaşıntısı, işitmede azalma, baş dönmesi, denge kaybı semptomlarını araştırmayı amaçlamaktayız.

\section{GEREÇ VE YÖNTEM}

Çalışmamız için Adıyaman Üniversitesi Girişimsel Olmayan Klinik Araştırmalar Etik Kurul Başkanlığı'ndan gerekli izin alınmıştır (Protokol no: 2018/9-21). Bu çalışma, Ocak 2017 ve Aralık 2017 yılları arasında Adıyaman Üniversitesi, Diş Hekimliği Fakültesi Ağız, Diş ve Çene Cerrahisi Kliniğine başvuran TMD bulunan hastalar ile yapıldı. 162'si kadın ve 52'si erkek olan 214 TMD'li hastanın tedavi öncesi verileri çalışmaya dahil edildi.

Tüm hastaların TMD problemleri klinik olarak incelendi. Tedavi öncesi verileri, tıbbi ve dental geçmişi, TMD şikayetlerinin geçmişini ve klinik belirti ve semptomlarının değerlendirilmesini içeriyordu. Hastaların seçiminde TMD/ATK (Tempromandibular eklem düzensizlikleri/Araştırma Teşhis Kriterleri) ${ }^{16}$ referans alındı. Hastalar ayrıca kulak ağrısı, kulak çınlaması, kulakta dolgunluk hissi, kulak kaşıntısı, işitmede azalma, baş dönmesi, denge kaybı dahil olmak üzere otolojik şikayetleri açısından sorgulandı.

Spesifik kulak semptomların ortaya çıkması öz rapor yoluyla elde edildi. ${ }^{1}$ Hastalara basitçe, son 2 ay içerisinde işitsel şikayetleri olup olmadığı soruldu. Bu sorular: 1. Kulak ağrısı: kulaklarınızın içinde veya çevresinde ağıı yaşıyormusunuz? 2. Kulak çınlaması: kulaklarınızda veya başınızda sesler duydunuz mu? (kulaklarda ses) 3. Kulakta dolgunluk hissi 4. Kulak kaşıntısı 5. İşitmede azalma 6. Baş dönmesi (vertigo: Çevrenizin veya çevrenizdeki eşyaların döndüğünü hissettiniz mi?) 7. Denge kaybı. Hastalar sorulara evet veya hayır şeklinde cevap verdi. Kulak semptomlarının seviyesi tahmin edilmedi.
$\mathrm{Bu}$ çalışmada elde edilen veriler IBM SPSS Statistics Version 22 paket programı ile analiz edildi. Elde edilen verilerin analizinde deskriptif istatistik kullanıldı.

\section{BULGULAR}

Bu çalışma, 162'si kadın ve 52'si erkek olmak üzere 214 TMD teşhisi konan hastaların klinik verilerinin retrospektif olarak incelenmesi ile yapıldı. Hastaların yaş aralığı 14 ile $54 \quad(28.48 \pm 9.65)$ arasındadır. 214 TMD teşhisi konan hastaların 65'inde (\%30.37) kulak semptomuna rastlanmadı. 149 hastada (\%69.63) ise en az bir kulak semptomu görüldü. Kulak semptomu bulunan hastaların 120'si kadın (\%80.5) ve 29'u ise erkektir (\%19.5). Kulak semptomları bulunan hastaların dağılımı tablo 1'de gösterilmiştir. Kulağa ait semptomların oranı ise kulak ağrısı 117 hastada (\%78.5), kulak çınlaması 77 hastada (\%51.7), kulakta dolgunluk hissi 56 hastada (\%37.6), kulak kaşıntısı 50 hastada (\%33.6), işitmede azalma 3 hastada (\%2), baş dönmesi 61 hastada (\%40.9), denge kaybı ise 50 hastada (\%33.6) gözlendi. Kulak semptomları arasında \%78.5 oranı ile kulak ağrısı en fazla görülürken, işitmede azalma \%2 oranı ile en az görülen semptom oldu. (Tablo 1.)

\section{Tablo 1.}

\section{Kulak semptomu bulunan hastaların dağılımı}

\begin{tabular}{|c|c|c|}
\hline $\begin{array}{l}\text { Kulak } \\
\text { semptomu }\end{array}$ & Var & Yok \\
\hline \multirow{2}{*}{$\begin{array}{l}\text { Kulak } \\
\text { Ağrısı }\end{array}$} & 117 & 32 \\
\hline & \%78.5 & $\% 21.5$ \\
\hline \multirow{2}{*}{$\begin{array}{l}\text { Kulak } \\
\text { Çınlaması }\end{array}$} & 77 & 72 \\
\hline & $\% 51.7$ & $\% 48.3$ \\
\hline \multirow{2}{*}{$\begin{array}{l}\text { Kulakta } \\
\text { Dolgunluk } \\
\text { hissi }\end{array}$} & 56 & 93 \\
\hline & \%37.6 & $\% 62.4$ \\
\hline \multirow{2}{*}{$\begin{array}{l}\text { Kulakta } \\
\text { Kaşıntı }\end{array}$} & 50 & 99 \\
\hline & \%33.6 & $\% 66.4$ \\
\hline \multirow{2}{*}{$\begin{array}{l}\text { İşitmede } \\
\text { azalma }\end{array}$} & 3 & 146 \\
\hline & 0,02 & 0,98 \\
\hline \multirow{2}{*}{$\begin{array}{l}\text { Baş } \\
\text { dönmesi }\end{array}$} & 61 & 88 \\
\hline & $\% 40.9$ & $\% 59.1$ \\
\hline \multirow{2}{*}{$\begin{array}{l}\text { Denge } \\
\text { Kaybı }\end{array}$} & 50 & 99 \\
\hline & \%33.6 & $\% 66.4$ \\
\hline
\end{tabular}




\section{TARTIŞMA}

1922 ylında Monson ${ }^{17}$ tarafından mandibula başının anormal lokalizasyonu nedeniyle meydana gelen ani işitme kaybı bulunan vaka raporunu yayınlamıştır. TMD ile kulak semptomları arasında ilişki olabileceği ilk kez bu vaka ile ortaya atılmıştır. Bunu takiben Decker ${ }^{18}$ TMD bulunan hastalarda işitme kaybı ve duymada bozulma hastalarını, Goodfriend ${ }^{19}$ TMD ile kulak çınlaması insidansı ile ilgili çalışma yayınlamıştır. Çiğneme sistemi disfonksiyonu ile kulak semptomların ilişkilendiren ilk hekimin Costen $^{20}$ olduğu varsayılmaktadır. Costen, stomatognatik sistem ile ilişkili şikayetli hastalarda kulak çınlaması, baş dönmesi ve kulak ağrısı semptomlarını rapor etmiştir.

TMD ile kulak semptomları arasındaki etiyolojik ilişkiyi açıklamak için çeşitli hipotezler öne sürülmüştür. ${ }^{5,9,14,21}$ TMD bulunan hastalarda kulak ağrısı TME ve kulak yapılarının anatomik yakınlığı ile açıklanabilmektedir. Diğer taraftan, kulak çınlamasına çiğneme ve tensor timpani kaslarının hiperaktivitesinin sebep olduğu varsayılmıştır. ${ }^{5-9}$

Literatürde TMD'ye eşlik eden kulak semptomlarını konu alan çalışmalar bulunmaktadır. TMD hastalarında bildirilen kulak semptomları prevelansı literatürde farklıık göstermektedir. ${ }^{1-4,9-11,22}$ Tuz ve ark. ${ }^{4} 200$ TMD hastasında kulak semptomlarının sıklığını araştırdıkları çalışmada hastaların \%22.5'inde herhangi bir semptom bulunmadığını, \%77.5'inde ise en az bir otolojik şikayet, $\% 50$ 'sinde kulak ağrısı ve \%45.5'inde kulak çınlaması olduğunu bildirmişlerdir. Wieckiewicz ve ark. ${ }^{23}$ TMD'li hastalarda kulak semptom oranının \%19 olduğu, Cooper ve Cooper ${ }^{24}$ TMD hastalarını değerlendirdikleri çalışmada \%79'unda kulak semptomlarının bulunduğunu, kulak ağrısı ve kulak çınlamasının her birinin $\% 53$ oranı ile en sık görülen semptomlar olduğunu belirtmişlerdir. Kitsoulis ve ark. ${ }^{25}$ TMD hastalarının \%28.44'ünde iki veya daha fazla kulak semptomunun, \%9.4'ünde ise dört veya daha fazla kulak semptomunun var olduğunu belirtmişlerdir. Sunduğumuz çalışmada TMD bulunan hastaların \%69.6'sında en az bir kulak semptomu bulunmaktadır. Çalışmamızda TMD'li hastalarda görülen kulak semptomları oranı literatür ile uyum göstermektedir.

Akhter ve ark. ${ }^{1}$ genç erişkin populasyonda yaptıkları çalışmada, kontrol grubuna kıyasla TMD bulunan hastalarda kulak çınlaması, baş dönmesi ve kulak ağrısı semptomlarının daha fazla görüldüğünü bildirmişlerdir. Kulak çınlaması ve baş dönmesinin daha sık karşılaşılan bulgu olduğu sonucuna varmışlardır. MaciejewskaSzaniec ve ark. ${ }^{26}$ TMD'li hastaların \%36.18'inde kulak semptomlarının var olduğunu ve TMD'ye eşlik eden en sık kulak semptomlarının ise kulakta tıkanma ve dolgunluk hissinin yanı sıra kulak ağrısı olduğunu belirtmişlerdir. Kusdra ve ark. ${ }^{27}$ ise TMD'li hastaların $\% 87$ 'sinde kulak semptomlarının var olduğunu ve en çok $\% 42$ oranı ile kulak çınlaması ve onu takiben \%39 oranı ile de kulak dolgunluğu semptomlarının bulunduğunu rapor etmişlerdir. Vasconcelos ve ark. ${ }^{28}$ TMD bulunan 100 hastanın 92'sine kulak semptomların eşlik ettiğini ve ileri TMD'li hastalarda kulak ağrısı, kulak çınlaması, kulak kaşıntısı ve kulakta dolgunluk hissinin en sık görülen semptomlar olduğunu bildirmişlerdir. Kadın hastalarda kulak ağrısı ve kulak kaşıntısının daha fazla bulunduğunu belirtmişlerdir. Çalışmamızda TMD'li hastarda en sık karşılaşılan kulak semptomunu kulak ağrısı, en çok görülen diğer semptomlar ise kulak çınlaması ve baş dönmesidir.

Mejersjö ve Naslund ${ }^{29}$ yaptıkları araştırmada TMD'li hastaların \%68'inde kulak semptomlarının bulunduğunu bildirmişlerdir. Bu hastalarda kulak dolgunluğu \%44 oranında, işitme bozukluğu ise \%37 oranında olduğu rapor edilmiştir. Ayrıca kadınlarda kulak ağrısı ve sese duyarlıık şikayetinin daha fazla bulunduğunu belirtmişlerdir. Ciancaglini ve ark. ${ }^{30}$ TMD'nin şiddeti ile kulak, burun ve boğaz semptomlarının ilişkisini araştırmışlardır. Yaptıkları çalışmanın sonucuna göre TMD'nin şiddeti ile sağırlık ve baş dönmesi arasında istatistiksel olarak anlamlı bir ilişki var iken, kulak çınlaması ve kulak ağrısı arasında istatistiksel olarak anlamlı bir ilişki olmadığı sonucuna varmışlardır. Chole ve Parker ${ }^{31}$ kulak çınlaması ve baş dönmesi ile TMD arasındaki ilişkiyi inceledikleri çalışmada TMD bulunan grupta kontrol grubuna kıyasla kulak çınlaması ve baş dönmesi semptomlarının daha fazla görüldüğünü rapor etmişlerdir. Çalışmamızda baş dönmesi diğer çalışmalar ile uyumlu iken, ${ }^{30,31}$ işitme azalma oldukça az oranda görüldü. Bunun nedenini diğer çalışmalarda ${ }^{29,30}$ işitme testleri yapıldığı için daha yüksek oranda olduğunu düşünmekteyiz.

Sunulan çalışmada TMD bulunan hastaların \%69.63'ünde kulak semptomu bulunurken, \%30.37'sinde ise kulak semptomu bulunmamaktadır. Hastaların \%78.5'inde kulak ağrısı, \%51.7'sinde kulak çınlaması, \%37.6'sında kulakta dolgunluk hissi, \%33.6'sında kulak kaşıntısı, \%2'sinde işitmede azalma, \%40.9'unda baş dönmesi, \%33.6'sında ise denge kaybı tespit edildi. Çalışmamızda kulak semptomu bulunan hastaların 120'si kadın (\%81.5) iken 29'u erkektir (\%19.5). TMD'ye kulak semptomları arasında en fazla kulak ağrısı, ikinci sırada kulak çınlaması ve en az ise işitmede azalma eşlik etmektedir.

TMD ile kulak semptomlarının araştııılığı çalışmalarda farklı kulak şikayetleri incelenmiştir. Pekkan ve ark. ${ }^{9} 25$ TMD teşhisi konulan hastaların 18'inde kulak ağrısı, 13'ünde kulak çınlaması, 14'ünde kulak dolgunluğu, 5 'inde baş dönmesi ve 2'sinde duymada azalma bulunduğunu belirtmişlerdir. Lam ve ark. ${ }^{2} 344$ TMD tanılı hastaların kulak ağrısı, kulak çınlaması, baş dönmesi ve 
duymada azalma oranlarını sırası ile \%67, \%64.1, \%65.2, \%62.2 olduğunu rapor etmişlerdir. Ferendiuk ve ark. ${ }^{10}$ da 1208 TMD'li hastanın \%5.71'inde kulak ağrısı, \%1.16'sında işitme bozukluğu, \%3.72'sinde kulak çınlaması, \%0.75'inde baş dönmesi bulunduğunu bildirmişlerdir. Manfredini ve ark. ${ }^{32} 238$ TMD hastasının \%30.4'ünde kulak çınlaması bulunduğunu rapor etmişlerdir. Literatürü incelediğimizde TMD ile ilişkili kulak semptomlarından bir tane veya en fazla beş kulak semptomunu araştıran çalışma bulunmaktadır. Sunulan çalışmada TMD teşhisi konulan hastalarda yedi kulak semptomu incelendi. Bu alanda yapılan kulak şikayetlerini içeren en geniş kapsamlı çalışma olmaktadır.

Kulak semptomları değerlendirilirken bazı çalışmalarda odyolojik testlerden faydalanılmıştır.,9,26 Bazı çalışmalarda da hastalara kulak semptomları var veya yok şeklinde formlar doldurularak yapılmıştır. ${ }^{1,3,10}$ Bizde Akhter ve ark. ${ }^{1}$ ile Ferendiuk ve ark.'nın ${ }^{10}$ çalışmalarını referans alarak hastalara kliniğimizde doldurduğumuz formları değerlendirerek bu çalışmayı planladık. Semptomlar var veya yok şeklinde değerlendirildi. Semptomların şiddeti hakkında bilgi edinilmedi.

\section{SONUÇ}

Çalışmamızda TMD teşhisi konulan hastalarda kulak ağrısı, kulak çınlaması, kulakta dolgunluk hissi, kulak kaşıntısı, işitmede azalma, baş dönmesi, denge kaybı gibi kulak semptomlarının varlığı araştırıldı. Sonuç olarak en fazla kulak ağrısı, ikinci sırada kulak çınlaması ve en az ise işitmede azalma olduğu belirlendi. Çalışmamızın gelecekte TMD bulunan hastalarda tedavi öncesi ve tedavi sonrası kulak semptomlarındaki iyileşme durumunu araştıran çalışmalara ışık tutacağını düşünmekteyiz. 


\section{KAYNAKLAR}

1. Akhter R, Morita M, Ekuni D, Hassan NMM, Furuta M, Yamanaka R, Matsuka R, Wilson D. Self-reported aural symptoms, headache and temporomandibular disorders in Japanese young adults. BMC Musculoskeletal Disorders 2013; 14: 1-7.

2. Lam DK, Lawrence HP, Tenenbaum HC. Aural symptoms in temporomandibular disorder patients attending a craniofacial pain unit. J Orofac Pain 2001; 15: 146-157.

3. Parker WS, Chole RA. Tinnitus, vertigo, and temporomandibular disorders. Am J Orthod Dentofacial Orthop 1995; 107: 153-158.

4. Tuz HH, Önder EM, Kişnişçi RS. Prevalence of otologic complaints in patients with temporomandibular disorders. J Orthod Dentofacial Orthop 2003; 123: 6203.

5. Myrhaug $\mathrm{H}$. The incidence of ear symptoms in cases of malocclusion and temporomandibular joint disturbances. Br J Oral Surg 1964; 2: 28-32.

6. Malkin DP. The role of TMJ dysfunction in the etiology of middle ear disease. Int J Orthod 1987; 25: 20-1.

7. Morgan DH. Tinnitus of TMJ origin a preliminary report. Cranio 1992; 10: 124-9.

8. Laughner BA, Larkin LH, Mahan PE. Discomalleolar and anterior malleolar ligaments: possible causes of middle ear damage during temporomandibular joint surgery. Oral Surg Oral Med Oral Pathol 1989; 68: 1422.

9. Pekkan G, Aksoy S, Hekimoğlu C, Oghan F. Comparative audiometric evaluation of temporomandibular disorder patients with otological symptoms. Journal of Cranio-Maxillo-Facial Surgery 2010; 38,: 231-4.

10.Ferendiuk E, Zajdel K, Pihut M. Incidence of Otolaryngological Symptoms in Patients with Temporomandibular Joint Dysfunctions. BioMed Research International 2014; 24: 1-5.

11.Toledo IP, Stefani FM, Porporatti AL, Mezzomo LA, Peres MA, Flores-Mir C, Canto GL. Prevalence of otologic signs and symptoms in adult patients with temporomandibular disorders: a systematic review and meta-analysis. Clin Oral Invest 2017; 21: 597-605.

12. Keersmaekers K, De Boever JA, Van Den Berghe L. Otalgia in patients with temporomandibular joint disorders. J Prosthet Dent 1996; 75: 72-6.

13. Rubinstein B. Tinnitus and craniomandibular disordersis there a link? Swed Dent J Suppl 1993; 95: 1-46.

14. Chole RA, Parker WS. Tinnitus and vertigo in patients with temporomandibular disorder. Arch Otolaryngol Head Neck Surg 1992; 118: 817-21.

15. Dolowitz DA, Ward JW, Fingerle DO, Smith CC. The role of muscular incoordination in the pathogenesis of the temporomandibular joint syndromes. Laryngoscope 1964; 74: 790-801.
16.Dworkin SF, LeResche L. Research Diagnostic Criteria for Temporomandibular disorders (RDC/TMD): criteria, examinations and specifications, critique. J Craniomandib Disord 1992; 6: 301-55.

17. Monson G. Some important factors which influence occlusion. Journal of the American Dental Association 1922; 9: 498-503.

18. Decker CJ. Traumatic deafness as a result of retrusion of the condyles of the mandible. Ann Otol Rhinol Laryngol 1925; 34: 519-27.

19. Goodfriend DJ. Symptomatology and treatment of abnormalities of the mandibular articulation. Dent Cosmos 1933; 75: 844-52.

20. Costen JB. A syndrome of ear and sinus symptoms dependent upon disturbed function of the temporomandibular joint. Am Otol Rhinol Larygol 1934; 43: 1-15.

21. Ash CM, Pinto OF. The TMJ and the middle ear: structural and functional correlates for aural symptoms associated with temporomandibular joint dysfunction. Int J Prosthodont 1991; 4: 517.

22.Tozoğlu S, Bayramoğlu Z, Özkan O. Outcome of otologic symptoms after temporomandibular joint arthrocentesis. The Journal of Craniofacial Surgery 2015; 26: 344-7.

23.Wieckiewicz M, Grychowska N, Wojciechowski K, Pelc A, Augustyniak M, Sleboda A, Zietek M. Prevalence and correlation between TMD based on RDC/TMD diagnoses, oral parafunctions and psychoemotional stress in Polish university students. BioMed research international 2014; 1-7.

24.Cooper BC, Cooper DL. Recognizing otolaryngologic symptoms in patients with temporomandibular disorders. Cranio: J Craniomandibular Pract 1993; 11: 260-7.

25. Kitsoulis P, Marini A, lliou K, Galani V, Zimpis A, Kanavaros P, Paraskevas G. Signs and symptoms of temporomandibular joint disorders related to the degree of mouth opening and hearing loss. BMC Ear, Nose Throat Disord 2011; 25: 11: 5.

26. Maciejewska-Szaniec Z, Maciejewska B, Mehr K, Piotrowski P, Michalak M, Wiskirska-Woznica B, Klatkiewicz T, Czajka-Jakubowska A. Incidence of otologic symptoms and evaluation of the organ of hearing in patients with temporomandibular disorders. Medical Science Monitor 2017; 23: 5123-9.

27.Kusdra PM, Stechman-Neto J, Leão BLC, Martins PFA, Lacerda ABM, Zeigelboim BS. Relationship between Otological Symptoms and TMD. Int Tinnitus J 2018 1; 22: 30-4. 
28.Vasconcelos BC, Barbosa LM, Barbalho JC, Araújo GM, Melo AR, Santos LA. Ear pruritus: a new otologic finding related to temporomandibular disorder. Gen Dent 2016; 64: 39-43.

29. Mejersjö C, Näslund I. Aural symptoms in patients referred for temporomandibular pain/dysfunction. Swed Dent J. 2016; 40: 13-20.

30. Ciancaglini R, Loreti P, Radaelli G. Ear, nose, and throat symptoms in patients with TMD: the association of symptoms according to severity of arthropathy. J Orofac Pain. 1994; 8: 293-7.

31. Chole RA, Parker WS. Tinnitus and vertigo in patients with temporomandibular disorder. Arch Otolaryngol Head Neck Surg 1992; 118: 817-21.

32. Manfredini D, Olivo M, Ferronato G, Marchese R, Martini A, Guarda-Nardini L. Prevalence of tinnitus in patients with different temporomandibular disorders symptoms. Int Tinnitus J 2014; 19: 47-51.

Yazışma Adresi:

Günay YAPICI YAVUZ

Adıyaman Üniversitesi Diş Hekimliği Fakültesi

Ağız, Diş ve Çene Cerrahisi AD

02000, Adıyaman, Türkiye

Tel : : +904162251598

E Posta: dtgunayyapici@hotmail.com 